\title{
THE ROLE OF PLATELET-RICH PLASMA IN THE TREATMENT OF DIABETIC FOOT ULCERS
}

\author{
By
}

\section{Mohamad Ahmed Abd El-Rahman, Omar Mokhtar Ibrahim Al-Hayeg, Al-Sayed Basiony Moghazy Aboulyazid and Abdullah Mustafa gaafar*}

Departments of General Surgery and Clinical Pathology*, Faculty of Medicine, Al-Azhar University

E-mail: mohamadabdo0100@gmail.com

\begin{abstract}
Background: Diabetic foot ulcer treatment places a considerable strain on the medical system, with long waiting time for healing. Platelet Rich Plasma allows effective treatment of many patients with hemostatic, anti-inflammatory and analgesic substances.

Objective: To find out the advantages and efficacy of Platelet Rich Plasma versus conventional ordinary dressing in management of diabetic foot ulcer and wound.

Patients and methods: This prospective randomized controlled study was conducted on 20 diabetic patients having non-healing feet ulcers. Patients were randomly allocated into two equal groups; Group A: Conventional ordinary dressing, and Group B: PRP dressing. Follow-up period was for 4-months.

Results: Most of ulcers healed within the estimated time for this study (16 weeks) or less and there were satisfactory results (less complications) in PRP group (B). Also, the rate of healing was good in group (B) with p-value $<0.05$.

Conclusions: PRP was an influential tool for treating chronic ulcers, so long as healing, reducing infection rates, besides its preventive action, which reduces amputation rates; So PRP is considered a very hopeful method for chronic ulcer dressing especially diabetic foot wounds than conventional ordinary dressing.
\end{abstract}

Keywords: Platelet Rich Plasma, Conventional Ordinary Dressing, Diabetic Foot Ulcer, Healing rates.

\section{INTRODUCTION}

Platelet-rich plasma (PRP) has been introduced as a new adjunct treatment for patients with chronic wounds. It is a concentration of platelets obtained from centrifuging the patient's own blood. It contains fibrin and high concentrations of growth factors, which are known to promote the healing of various organs. This treatment was first reported in the mid-1980s. Since then, its use has increased dramatically in the fields of reconstructive plastic surgery, spine surgery, orthopedics, and oral and maxillofacial surgery. It was first proposed for use in chronic wound treatment in the early 1990s.5,6 However, its use in wound treatment is not as widespread as in other fields, and currently only a limited number of institutions offer this treatment (Yotsu et al., 2015).

The pathophysiology of diabetic foot ulcers lies on the mixed effects of sensory, motor, and autonomic neuropathy along with abnormal foot mechanics, structural deformities, microvascular angiopathy, and compromised immune system. The 
aforementioned factors often coexist with peripheral arterial disease (PAD), which compromises perfusion on a macrovascular level having a substantial deteriorating effect and indicating a worse prognosis. The true prevalence of PAD in diabetic patients has been difficult to determine because pain perception may be blunted in many of them while others due to a poor general status undertake only minimal physical activity in their daily practice, which is not enough for ischemic symptoms to develop. Accordingly, diabetic patients with PAD are more likely than no diabetic patients to present advanced disease at initial diagnosis, often with an ulcer and critical limb ischemia (CLI) as the first symptoms (Kontopodis et al., 2016).

The annual incidence of foot ulceration is estimated to be approximately $1 \%-4 \%$, and its prevalence ranges from $4 \%$ to $10 \%$, whereas, the lifetime risk for the development of a diabetic foot ulcer in patients with diabetes ranges from $15 \%$ to as high as 25\% (Amin and Doupis, 2016).

The aim of this prospective study was to find out the advantages and efficacy of Platelet Rich Plasma versus conventional ordinary dressing in management of diabetic foot ulcer and wound.

\section{PATIENTS AND METHODS}

The local ethical committee of AlAzhar University approved the trial and written fully informed patients' consents were obtained about the two methods of dressing benefits, risks, alternative interventions and possible complications. The current study was conducted at AlAzhar University Hospitals from June 2019 to December 2019. This prospective randomized controlled study was conducted on 20 diabetic patients having non-healing feet ulcers. Patients were randomly allocated randomly into two equal groups: Group A: Conventional ordinary dressing, and Group B: PRP dressing.

Criteria of the patients: Age between 30-70 years old, diabetic patients from either type of diabetes (type I or type II) in a controlled status with non-healed feet ulcers, ulcer for 3 to 6 months, The foot ulcer size ranged from 5 to $11 \mathrm{~cm}$ diameter size. Patients hoped for revascularization surgery, have normal peripheral platelet count (>150 000/mm3) and hemoglobin $>10.5 \mathrm{~g} / \mathrm{dl}$.

Patients excluded from this study were pregnant women, patients with ischemic changes of foot, patients with severe cardiovascular disorders, patients were not hoped for revascularization surgery, hemoglobin $<10 \mathrm{gm} / \mathrm{dL}$, platelet count $<150,000 / \mathrm{dL}$, associated lymphedema and patients refused to donate blood for the procedure.

All patients with non-healing feet ulcers underwent formal assessment and investigations to recognize the risk factors and treatment of diabetic foot disorders improving outcomes, and limiting the risk of lower extremity amputation.

Group A was treated by conventional ordinary dressing. I.e. with irrigation of the ulcer with saline, local antiseptic and antibiotic, and the patient packing the wound by vaseline gauze and then dressed.

Group B was treated by platelet rich plasma therapy, had PRP as their dressing protocol, PRP was applied to the diabetic 
foot after being prepared (within half an hour after preparation), followed by vaseline gauze and then dressed. The frequency of change of dressing was once weekly. Up to 16 weeks, or stopped whenever healing occurred.

Each case was sprayed with PRP in ulcers edges (sub dermal) and its floor (if deep). PRP was prepared from their own blood (autologous PRP). Venous blood samples were drawn into $5 \mathrm{ml}$ sterile tubes containing an anticoagulant (sodium citrate). Whole blood was centrifuged at $300 \times \mathrm{g}$ for 5 minutes at $18^{\circ} \mathrm{C}$. the first centrifugation was called 'soft spin' (1007 $\mathrm{g}$ ), which allowed blood separation into three layers, namely bottommost red blood cell (RBC) layer $(55 \%$ of total volume),topmost a cellular plasma layer called platelet-poor plasma (PPP; $40 \%$ of total volume), and an intermediate PRP layer (5\% of total volume) called the 'buffy coat'. The upper fraction (PRP1) was separated without disturbing the buffy coat, and was transferred into a sterile tube. The PPP, PRP and some RBCs, i.e. the upper two layers and very minimal 'unavoidable' amount of bottom layer, were transferred into another tube without an anticoagulant. This tube underwent a second centrifugation $(447 \cdot 5 \mathrm{~g})$ called 'hard spin'.

This allowed the platelets (PRP) settled at the bottom of the tube with a very few RBCs. A cellular plasma, PPP ( $80 \%$ of the volume), was found on the top. Most of the PPP was removed with a syringe and the remaining PRP was shaken well. PRP1 was centrifuged at $700 \times \mathrm{g}$ during 17 minutes at $18^{\circ} \mathrm{C}$. The platelet pellet obtained from PRP1 was resuspended in one $\mathrm{ml}$ PPP (PRP2). Platelet activation was performed immediately by adding $0.5 \mathrm{ml} \mathrm{CaCl2}$. Application was done immediately after activation in ulcers edges and floor.

The patients were advised to avoid pressure on ulcer area. Special shoe with molded insole was used. Elevation of the feet was recommended during setting or lying down to decrease edema. The patients were revised once weekly throughout the treatment course.

Patients were evaluated for the rate of healing of the ulcer in about 4 months and this evaluation was carried out by measuring the ulcer's dimensions (length and width) using metric tape at the initial visit and then every week. Antibiotics were used when there was an infection.

\section{Statistical analysis:}

From the first visit of the patient, all information were collected to an excel file Excel 2019 (Microsoft Office, Microsoft, Washington D.C, USA). The quantitative data were presented as mean, standard deviations and ranges when their distribution found parametric and median with inter-quartile range (IQR) when their distribution found non parametric. Qualitative variables were presented as number and percentages. According to normality assumption of wound changes (healing rate /week in $\mathrm{cm}$ ) we used MannWhitney-U test for non-parametric data throughout the duration of study at weeks four, eight and twelve, as data not normally distributed. The p-value $<0.05$ was considered statistically significant. Data were analyzed using Statistical Package for the Social Sciences version 20.0 (SPSS, Inc., Chicago, IL, USA). 


\section{RESULTS}

This study was a prospective study done in Al-Azhar University hospitals including 20 diabetic patients having non healed feet ulcers were followed up for six months; patients were divided into two groups: Group A: including 10 patients underwent conventional ordinary dressing. Group B: including 10 patients underwent PRP dressing as their protocol of treatment.
The age ranged from 49 to 70 years with a mean of $58.60 \pm 8.23$ years in group $A$ and ranged from $48-65$ years with a mean of $57.70 \pm 5.1623$ years in group B. All patient presented by non-healed feet ulcers \& none of them was presented with any other symptoms, the majority of patients were males $(70 \%)$ in group B (Table 1).

Table (1): Demographic and clinical data of both studied groups

\begin{tabular}{|c|c|c|}
\hline Groups & Conventional & PRP \\
\hline Parameters & $\mathrm{N}=10$ & $\mathrm{~N}=10$ \\
\hline Nge (yrs) mean. \pm SD.range & $58.60 \pm 8.235(49-70)$ & $57.70 \pm 5.16(48-65)$ \\
\hline Sex M: F & $5(50 \%): 5(50 \%)$ & $7(70 \%): 3(30 \%)$ \\
\hline Hypertension & $6(60 \%)$ & $7(70 \%)$ \\
\hline smoking & $6(60 \%)$ & $8(80 \%)$ \\
\hline BMI & $28.5 \pm 4.43$ & $27.5 \pm 4.35$ \\
\hline Obesity ( $\geq \mathbf{3 0})$ & $3(30 \%)$ & $4(40 \%)$ \\
\hline Diabetes time (yrs)mean. \pm SD. & $15.50 \pm 7.46$ & $12.10 \pm 4.96$ \\
\hline Infection & $4(40 \%)$ & $2(20 \%)$ \\
\hline Hb & $9.7 \pm 1.04$ & $10.39 \pm 1.45$ \\
\hline HBa1c & $7.18 \pm 1.02$ & $7.38 \pm 1.08$ \\
\hline Plt count & $236042 \pm 64746$ & $279568 \pm 62960$ \\
\hline
\end{tabular}

HbA1C, glycosylated hemoglobin; Hb, hemoglobin; plt, platlets

Ulcer diameter mean difference between the 2 groups was not statistically significant $(\mathrm{P}$ value $>0.05)$. The total period taken by the 2 groups measured better for PRP group than conventional dressing group.

The platelet rich plasma (PRP) have shown to be more effective than the conventional antiseptic dressing after the 4th week with higher rate of healing per week, the difference of the healing rate between the 2 groups was statistically significant $(\mathrm{P}$ value $<0.05)$. The same effect was shown at the 8th week as regard the number of the ulcer healed for the PRP group VS the conventional group with better healing rate for the PRP group, but the difference of the healing rate between the 2 groups was not statistically significant $(\mathrm{P}$ value $>0.05)$. At the 12 th week the conventional dressing have shown higher rate of healing than the PRP dressing, the data was statistically significant $(\mathrm{P}$ value $<0.05$ )but the overall results group $\mathrm{B}$ healing occur before and faster than group A healing (Table 2). 
Table (2): Healing rates and ulcer diameter of studied groups

\begin{tabular}{|c|c|c|c|}
\hline $\begin{array}{l}\text { Groups } \\
\text { Parameters }\end{array}$ & Conventional & PRP & p-value \\
\hline $\begin{array}{l}\text { Ulcer diameter } \\
\text { mean } \pm \text { SD }\end{array}$ & $8 \pm 1.97$ & $7.9 \pm 1.33$ & $>0.05$ \\
\hline $\begin{array}{c}\text { No.of weeks } 100 \% \\
\text { healing } \\
\text { Median (IQR) } \\
\text { range }\end{array}$ & $\begin{array}{c}12.5(10.5-14.5) \\
0-16\end{array}$ & $\begin{array}{c}6(5-7) \\
5-9\end{array}$ & $<0.05$ \\
\hline $\begin{array}{c}4 \text { weeks } \\
\text { Median (IQR) } \\
\text { range (cm) } \\
\text { Median (IQR) } \\
\text { range (cm/week) } \\
\end{array}$ & $\begin{array}{c}2(1.75-2.25) \\
1-3 \\
0.5(0.43-0.56) \\
0.25-0.75 \\
\end{array}$ & $\begin{array}{c}5(4.1-5.9) \\
3.5-8 \\
1.25(1-1.47) \\
0.88-2 \\
\end{array}$ & $\begin{array}{l}<0.05 \\
<0.05\end{array}$ \\
\hline $\begin{array}{c}8 \text { weeks } \\
\text { Median }(\mathrm{IQR}) \\
\text { range }(\mathbf{c m}) \\
\text { Median }(\mathrm{IQR}) \\
\text { range }(\mathbf{c m} / \text { week) }\end{array}$ & $\begin{array}{c}2.5(2.25-2.75) \\
1.5-3 \\
0.62(0.49-0.75) \\
0.38-0.75\end{array}$ & $\begin{array}{c}2.5(1-3.9) \\
0.5-5 \\
0.62(0.26-0.98) \\
0.13-1.25\end{array}$ & $\begin{array}{l}>0.05 \\
>0.05\end{array}$ \\
\hline $\begin{array}{c}12 \text { weeks } \\
\text { Median }(\mathrm{IQR}) \\
\text { range }(\mathbf{c m}) \\
\text { Median }(\mathrm{IQR}) \\
\text { range }(\mathrm{cm} / \text { week) }\end{array}$ & $\begin{array}{c}2.25(1.95-2.55) \\
0.5-3 \\
0.56(0.48-0.64) \\
0.13-0.75 \\
\end{array}$ & $\begin{array}{c}0(0) \\
0-0.5 \\
0(0) \\
0-0.13\end{array}$ & $\begin{array}{l}<0.05 \\
<0.05\end{array}$ \\
\hline
\end{tabular}

\section{DISCUSSION}

PRP provides almost all of the growth factor required for healing. It exhibits two important roles for wound healing. Firstly, processed gel forms a barrier to prevent the bacteria contamination. Secondly, the growth factors from platelets trigger wound healing. Platelets also promote the secretion of biologically active proteins, including growth factors such as plateletderived growth factor, transforming growth factor (TGF)- $\beta$, TGF- $\beta 2$, and epidermal growth factor (EGF). The release of these growth factors into the wound may create an environment more conducive to tissue repair and could accelerate postoperative wound healing (Zhang et al., 2017).

The role of PRP as a local dressing is to provide the required growth factors locally at the wound area; this role is suggested to be beneficial because diabetic foot ulcers are deficient in growth factors (Tran et al., 2014).

This study showed the effectiveness of PRP in promotion of healing of diabetic feet ulcers, besides its preventive action, which reduces amputation rates, the results of the systematic review with meta-analysis published by Carter et al. suggest that PRP therapy can positively influence wound healing and associated factors such as pain and infection in both chronic wounds (Carter et al., 2011).

In the this study conducted on 20 patients with chronic ulcers, the patients ages were ranged from 49 to 70 years with a mean of $58.6 \pm 8.23$ years in group $\mathrm{A}$ and ranged from 48 to 65 years with a mean of $57.7 \pm 5.16$ years, The majority of patients were males (60\%) and we found that age and gender had no effect on rate 
of healing. According to study proposed by (Saad Setta et al. (2011) concluded that sex and age are insignificant in correlation with rate of healing of their ulcers. In this study, 10 patients were treated with autologous PRP and subcutaneous injections of PRP in and around the wound periphery versus 10 patients with conventional dressing by saline and local antiseptics and antibiotics. PRP patients showed healing of the wound with reduction in healing time compared to ordinary dressing, according to study proposed by Saad Setta et al. (2011) showed that healing in PRP group was significantly faster.

Kakudo et al. (2012) treated five cases of intractable skin ulcer with autologous PRP, among which three ulcers healed completely within 4 weeks and epithelialization of wound occurred within 6.6 weeks on average.

In this study, rate of healing per week was greater during the first 8 weeks in PRP group and starts to decline afterward. Ahmed et al. (2017) showed the same concept of healing rate after the first 8 weeks.

\section{CONCLUSION}

PRP is a prevailing defense for healing chronic ulcers, dropping infection rates, besides its defensive action, which decreases amputation rates; So PRP is considered a very talented technique for chronic ulcer dressing especially diabetic foot wounds.

Conflict of interests: The authors declared that there were no conflicts of interest regarding the publication of this paper.

\section{REFERENCES}

1. Ahmed, M., Reffat, S. A., Hassan, A., and Eskander, F. (2017): Platelet-rich plasma for the treatment of clean diabetic foot ulcers. Annals of vascular surgery, 38: 206-211.

2. Amin, N. and Doupis, J. (2016): Diabetic foot disease: From the evaluation of the "foot at risk" to the novel diabetic ulcer treatment modalities. World Journal of Diabetes, 7(7): 153-164.

3. Carter M.J., Anderson C. and Wilson J. (2011): The clinical relevance of treating chronic wounds with an enhanced nearphysiological concentration of platelet rich plasma gel. Advances in skin \&Wound care, 24(8):357368 .

4. Kakudo, N., Kushida, S., Ogura, T., Hara, T., Suzuki, K. and Kusumoto, K. (2012): The use of autologous platelet-rich plasma in the treatment of intractable skin ulcer: A case series. Open Journal of Regenerative Medicine, 1:2932.

5. Kontopodis, N., Tavlas, E., Papadopoulos, G., Pantidis, D., Kafetzakis, A., Chalkiadakis, G., and Ioannou, C. (2016): Effectiveness of platelet-rich plasma to enhance healing of diabetic foot ulcers in patients with concomitant peripheral arterial disease and critical limb ischemia. 
The International Journal of Lower Extremity Wounds, 15(1): 45-51.

6. Saad Setta H, Elshahat A, Elsherbiny $\mathrm{K}$, Massoud $\mathrm{K}$ and Safe I. (2011): Platelet-rich plasma versus platelet-poor plasma in the management of chronic diabetic foot ulcers: a comparative study. Int. Wound J.; 8:307-312.

7. Tran, T. D. X., Le, P. T. B., \& Van Pham, P. (2014): Diabetic foot ulcer treatment by activated platelet rich plasma: a clinical study. Biomedical Research and Therapy, 1(2): 37-42.
8. Yotsu, R. R., Hagiwara, S., Okochi, H. and Tamaki, T. (2015): Case series of patients with chronic foot ulcers treated with autologous platelet-rich plasma. The Journal of dermatology, 42(3): 288-295.

9. Zhang, Y., Deng, H. and Tang, Z. (2017): Efficacy of cellular therapy for diabetic foot ulcer: a meta-analysis of randomized controlled clinical trials. Cell transplantation, 26(12): 19311939. 


\section{دور البلازما المشبعة بالصفائح الدموية فى علاج قرح القدم

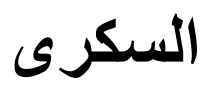

محمد أحمد عبد الرحمن، عمر مختار إبراهيم الهايج، السيد بسيونى مغازى ابواليزيد، عبدالله مصطفى جعفر

\section{قسمى الجراحة و الباثولوجيا الاكلينيكية**، كلية الطب، جامعة الازهر}

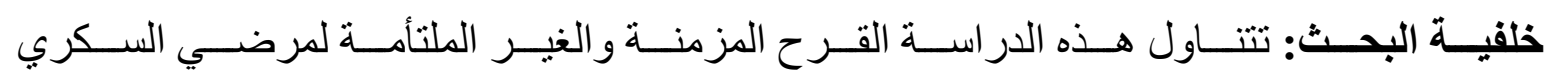

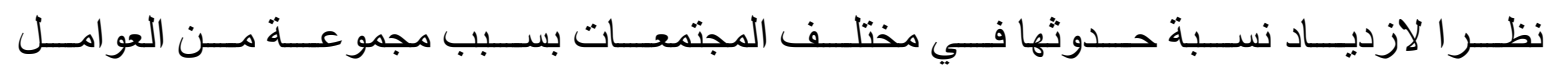

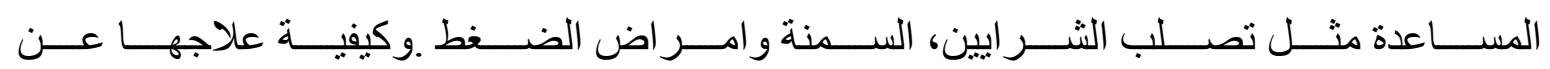

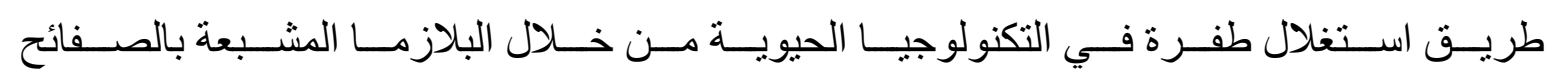
الدموية.

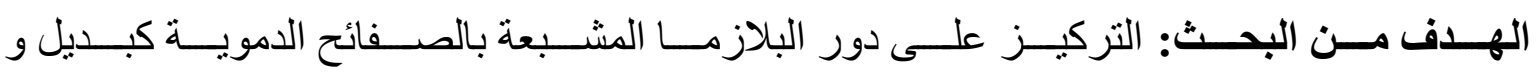

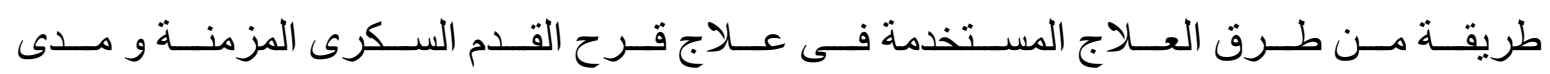
فعاليتها فى سر عة التئام القرح.

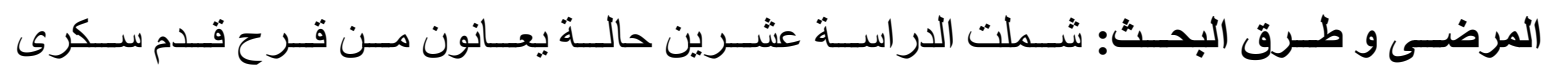

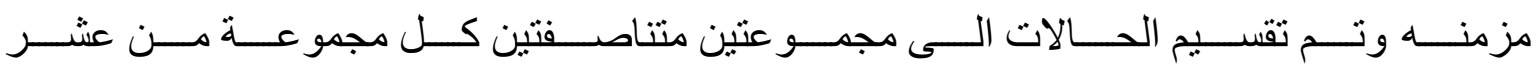

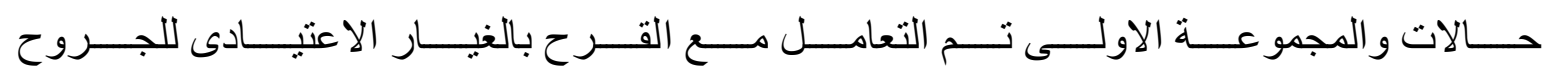

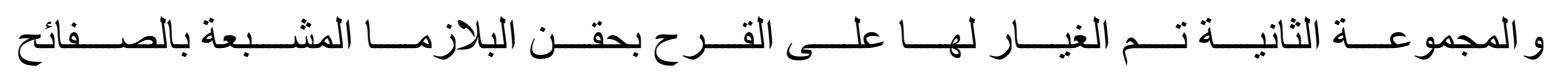

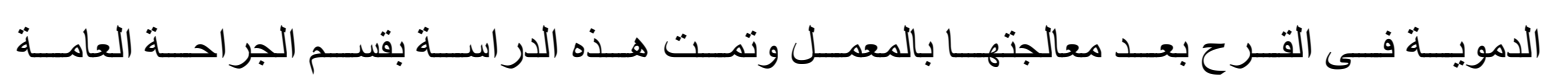
بمستشفيات جامعة الازهر في الفترة من يونيو 9201 الى ديسمبر 2019.

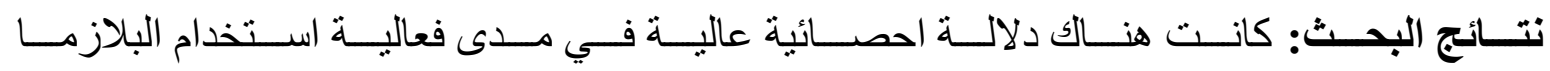

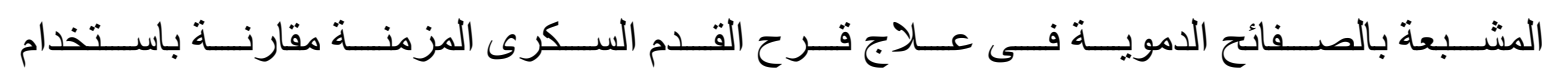
الغيار الاعتيادى فى التعامل مع القرح.

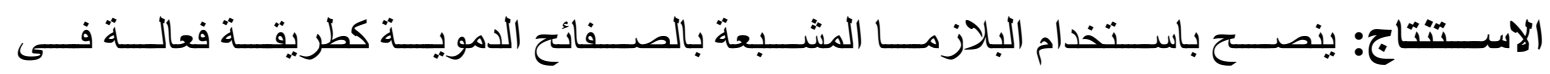
إلتنئام القرح المزمنة وآمنة و فعالة فى إرتفاع معدل الالتنئام. 